\title{
Treating Newly Diagnosed Epilepsy: The Canadian Choice
}

\author{
J.G. Burneo, R.S. McLachlan
}

\begin{abstract}
Background: Choosing an antiepileptic medication to treat a patient with epilepsy can be a complicated process during which the treating physician must base her or his decision on efficacy and safety of each of many available drugs. The lack of comparative studies between medications is one of the reasons. Methods: We conducted a survey on the management of newly diagnosed epilepsy in adult patients. The surveyed were adult and pediatric neurologists with a subspecialty interest in epilepsy who were working in academic institutions or private practice across Canada. Scenarios presented were grouped in categories according to the epilepsy syndrome (absence epilepsy, juvenile myoclonic epilepsy, undetermined idiopathic generalized epilepsy, symptomatic or cryptogenic partial epilepsy, and unclassified epilepsy), the patient's gender and age. First and second step in medical treatment for status epilepticus were surveyed as well. Results: Forty one of 64 experts responded the survey (responder rate of 66\%). The results revealed a consensus among Canadian epileptologists that the first choice of antiepileptic medication in generalized epilepsies was between valproate in men (chosen by $88 \%$ of respondents) and lamotrigine in women. In localization-related epilepsies, carbamazepine was the preferred drug of choice (chosen by $90 \%$ of respondents). In the treatment of status epilepticus, an initial intravenous dose of lorazepam ( $95 \%$ of respondents), followed by a second dose of lorazepam or intravenous phenytoin in case the initial dose of lorazepam failed, were the treatments preferred.
\end{abstract}

RÉSUMÉ: Traitement de l'épilepsie lors du diagnostic initial : le choix canadien. Contexte : Le choix d'un antiépileptique pour traiter un patient épileptique peut être un processus compliqué. Le médecin traitant doit baser sa décision sur l'efficacité et la sécurité de chacun des nombreux médicaments disponibles. Le manque d'études comparatives entre les médicaments est une des raisons à la base de ce problème. Méthodes : Nous avons effectué une enquête sur le traitement des nouveaux cas d'épilepsie chez l'adulte auprès des neurologues pédiatriques et adultes, ayant un intérêt particulier pour l'épilepsie et travaillant en milieu académique ou en pratique privée au Canada. Les scénarios présentés étaient regroupés en catégories selon le syndrome épileptique (absence épileptique, épilepsie myoclonique juvénile, épilepsie généralisée idiopathique indéterminée, épilepsie partielle cryptogénique ou symptomatique et épilepsie non classée), le sexe et l'âge du patient. On a également inclus la première et la seconde étape du traitement médical de l'état de mal épileptique. Résultats : Quarante et un des soixante et quatre experts ont répondu à l'enquête (taux de réponse de $66 \%$ ). Les résultats ont montré qu'il existe un consensus parmi les épileptologues Canadiens concernant le choix de la médication antiépileptique dans les épilepsies généralisées, soit le valproate chez l'homme (choisi par 88\% des répondants) et la lamotrigine chez la femme. Dans les épilepsies dont le foyer est localisé, la carbamazépine était le médicament de choix de 90\% des répondants. Dans le traitement de l'état de mal épileptique, $95 \%$ des répondants ont opté pour une dose initiale intraveineuse de lorazépam, suivie d'une seconde dose de lorazépam ou de l'administration intraveineuse de phénytoïne si la dose initiale de lorazépam n'a pas été efficace.

The therapeutic options for the treatment of epilepsy nowadays are innumerable. Over the past 15 years, new medications, new formulations for older drugs, and the vagus nerve stimulator have been approved. ${ }^{1,2}$ However, very few clinical trials have compared the different available treatments, and it is therefore difficult to establish a hierarchy of treatments and therapeutic strategies adapted to the various types of epilepsy.

In this new world of evidence-based clinical practice, the highest level of evidence comes from very well done metaanalyses, as they compare medication efficacy and tolerability using data derived from initial randomized controlled clinical trials. ${ }^{3,4}$ However, these have limitations. The most important is the fact that the different patient populations and study designs used in the initial clinical trials are not uniform, making direct comparisons less reliable..$^{5,6}$

From the Epilepsy Programme, London Health Sciences Center, University of Western Ontario, London, Ontario, Canada.

ReCEIVED OCTOBER 23, 2006. ACCEPTED In FINAL FORM February 24, 2007. Reprint requests to: Jorge G. Burneo, 339 Windermere Road, London, Ontario, N6A 5A5, Canada. 
Next in the hierarchy of evidence, we have the randomized controlled trials. Most of these studies are done against placebo, which can have a high magnitude non-pharmacological effects. ${ }^{7}$ These trials are usually performed in patients with high resistance to treatment, not representing the "standard" epilepsy population in which more than $50 \%$ are controlled with one antiepileptic drug (AED). ${ }^{8}$ Other studies offer selected comparisons between two drugs, usually an old AED and a new one, or between two new ones.

Although practicing physicians may have some knowledge of these published studies, they are more likely to rely on clinical summaries or the advice of clinicians with special expertise in the field of epilepsy when making decisions about treatment. ${ }^{9-13}$ We conducted a survey aiming to summarize the experience of Canadian epileptologists to determine if there is a consensus on the modalities of therapeutic management of newly diagnosed epilepsy or in cases of failure of first-line monotherapy. Two similar studies were undertaken with US and French epileptologists, ${ }^{14,15}$ which led to the establishment of easy-to-use therapeutic recommendations concerning the choice of specific drugs for different epilepsy syndromes in various clinical contexts in the USA and France. Since both the availability of the diverse AEDs and the prescribing habits of physicians vary from country to country, ${ }^{16}$ we predicted there would be differences in the results of a Canadian survey compared to those two countries.

\section{Materials ANd Methods}

\section{The epileptologists}

Sixty-four Canadian epileptologists were identified. An epileptologist is defined as a neurologist with a clinical practice largely dedicated to the care of patients with epilepsy. Most have had extra training in an epilepsy center, after his/her neurology training. They were identified from the list of members of the Canadian League Against Epilepsy and the list of members of the Canadian Society of Clinical Neurophysiologists. Because the survey focuses on adolescent- and adult-onset epilepsies, both pediatric and adult epileptologists were surveyed.

\section{The survey}

The survey consisted of four parts (Appendix). The first part identified epileptologists treating adults, pediatric, or both groups of patients. The second part obtained information about a therapeutic strategy adopted after failure of a first monotherapy. The options proposed were substitution monotherapy instituted within a few days or a few weeks, addition of a second AED and replacement monotherapy after a few months, or concomitant administration of a second AED as an early polytherapy.

The third part of the questionnaire identified the AED used for monotherapy in four specific clinical contexts: young men without any other medical problem, women of childbearing age, and the elderly. For each group, five clinical scenarios were presented: Idiopathic generalized epilepsy, juvenile myoclonic epilepsy, absence epilepsy, symptomatic or cryptogenic localization-related epilepsy, and unclassified epilepsy. In the elderly group, juvenile myoclonic epilepsy and absence epilepsy were not considered.
The fourth part focused on the management of status epilepticus. We asked about first line of therapy, and options after the first AED fails.

The answers were graded from 1 to 5 for each AED as follows,

$1=$ Extremely appropriate: it is your AED of choice (you may have several)

$2=$ Appropriate: the AED you use the most after your first choice $3=$ Sometimes useful: an AED you sometimes use (i.e. in case of failure or contraindication of the other $A E D)$

$4=$ Rarely useful=an AED that you rarely (or never) use or only in special cases

$5=$ Potentially harmful or totally inadequate

\section{Data Analysis}

The survey was mailed three times to improve response rate, and the responses were collected anonymously. The results of the survey were analyzed descriptively by giving the numbers and the percentage of each answer for the different situations presented. Tables were created using MS Excel 2003 (Redmond, WA). For the evaluation of the results in the treatment of status epilepticus, chi-square goodness-of-fit test was used, using SAS 9.0 .

\section{RESULTS}

The survey was completed by 41 of the 64 experts for a response rate of $66 \%$. Twelve $(29 \%)$ epileptologists treated exclusively pediatric patients, seventeen $(42 \%)$ only adult patients, and twelve (29\%) both groups of patients.

The strategy adopted after failure of the first monotherapy, included the following approaches: twelve chose immediate substitution monotherapy; twenty-eight chose add-on treatment, then monotherapy substitution after proven efficacy of the second antiepileptic agent; and only one chose add-on therapy with a second antiepileptic agent. After failure of the second option, two chose another substitution with monotherapy; sixteen chose add-on treatment, then monotherapy substitution after proven efficacy of the third antiepileptic agent; nineteen chose add-on therapy with a second antiepileptic agent; three chose to refer the patient to a surgical center to consider evaluation for epilepsy surgery; and one chose the use of ketogenic diet.

\section{Selection of first-line AED}

\section{Idiopathic generalized epilepsy (IGE)}

In young men without other medical problems (Figure 1)

Valproate (VPA) and lamotrigine (LTG) were the drugs chosen by the majority of epileptologists as the first-line treatment for Idiopathic generalized epilepsy. Valproate was considered as extremely appropriate by $88 \%$ of epileptologists, and LTG by $37 \%$. The third place was occupied by levetiracetam (LEV), which was considered "appropriate" by $46 \%$ of epileptologists, and then topiramate (TPM) by $44 \%$. The AEDs considered inadequate were vigabatrin (VGB) (56\%), gabapentin (GBP) (39\%), tiagabin (TGB) (37\%), ethosuximide (ETX) $(27 \%)$, and the vagus nerve stimulator (VNS) (24\%). VPA can therefore be considered as the reference drug. 


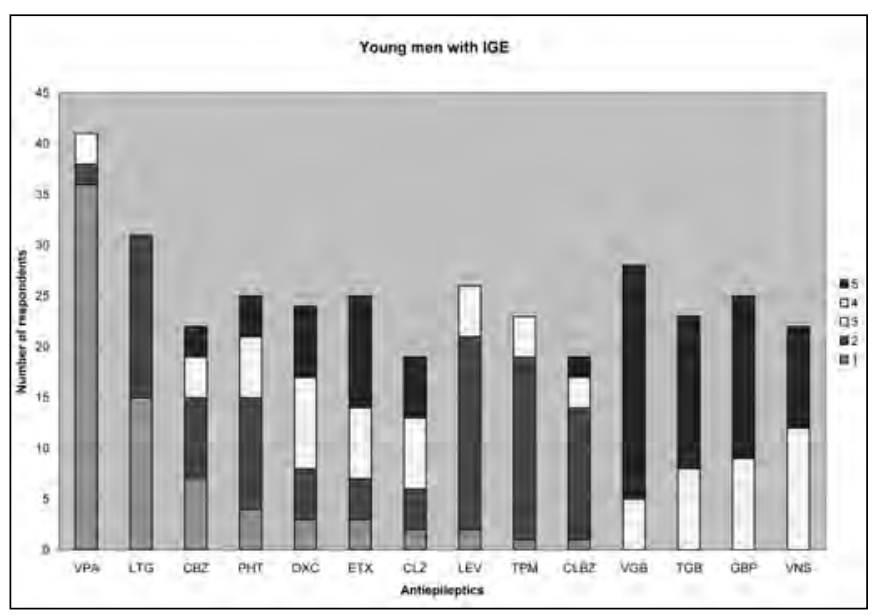

Figure 1: Responses chosen by Canadian epileptologists in cases of men with Idiopathic Generalized Epilepsy (IGE). PHT = phenytoin, VPA = valproate, $L T G=$ lamotrigine, $G B P=$ gabapentin, $T P M=$ topiramate, $O X C=$ oxcarbazepine, $L E V=$ levetiracetam, $V G B=$ vigabatrin, $T G B=$ tiagabine, $E T X=$ ethosuximide, $C L Z=$ clonazepam, $C L B Z=$ clobazam, $V N S=$ vagus nerve stimulation, $C B Z=$ carbamazepine, $P b=$ phenobarbital. The legend seen in this figure is the same for all 5 figures, with each number represented each option given as an answer.

\section{Women of childbearing age}

Lamotrigine was considered "extremely appropriate" by $78 \%$ of epileptologists, VPA by $41 \%$ and TPM by $31 \%$. Considered "appropriate" was LEV by $41 \%$ and CLBZ by $29 \%$. Considered less useful were VGB (85\%), VNS (78\%), TGB (65\%), GBP (54\%), PB (54\%), and PHT (42\%)

\section{Absence Epilepsy $(A E)$ \\ Young men}

Valproate was considered the first option for $89 \%$ of epileptologists, while ETX was considered to be 'extremely appropriate' by $65 \%$. LTG (39\%) and TPM (40\%) were considered 'appropriate as well. VGB (84\%), CBZ (80\%), OXC (74\%), VNS (71\%), PHT (67\%), and PB (59\%) were considered inadequate.

\section{Women of childbearing age}

In this group of patients, LTG was considered to be the most appropriate drug by $64 \%$ of epileptologists, together with ETX (41\%). VPA was considered 'appropriate' by $34 \%$, as well as LEV (41\%), TPM (38\%), CLBZ (37\%), and CLZ (30\%). VNS (87\%), VGB (85\%), PHT (73\%), CBZ (69\%), GBP (65\%), and PB $(58 \%)$ were considered 'inadequate'.

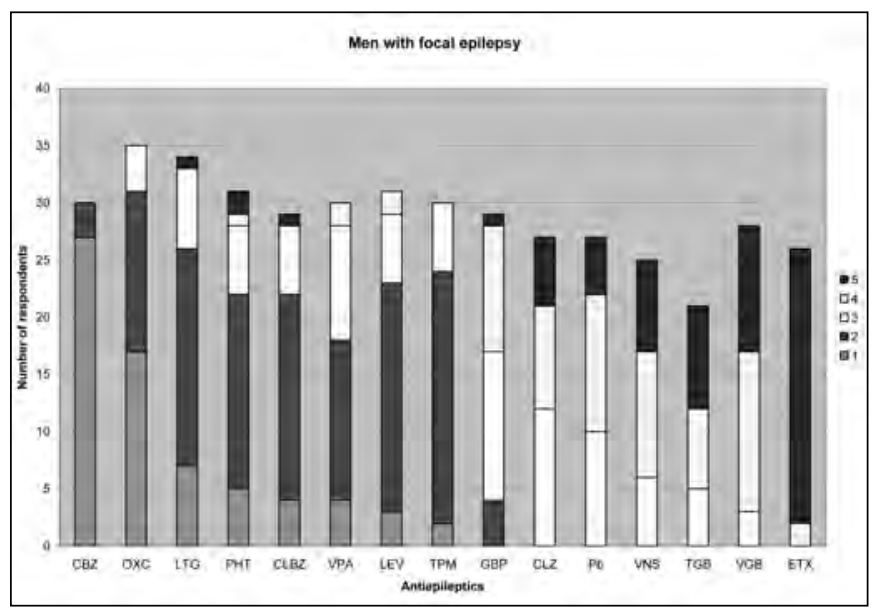

Figure 2: Responses chosen by Canadian epileptologists in cases of men with Localization-Related Epilepsy (LRE)

\section{Symptomatic or cryptogenic localization-related or focal epilepsy}

Young men (Figure 2)

Carbamazepine was by far the first choice in this group, chosen by $90 \%$ of epileptologists, followed by Oxcarbazepine (OXC) (49\%). 'Appropriate' medications were TPM (73\%), 
LEV (64\%), CLBZ (62\%), LTG (56\%), VPA (47\%), and GBP (45\%). PB was considered to be 'rarely useful' by $44 \%$, VGB by $50 \%$, and TGB by $43 \%$.

\section{Women of childbearing age}

Carbamazepine remained the first picked by $82 \%$ of the respondents, followed by LTG (62\%) and OXC (31\%). Considered 'appropriate' were TPM by $59 \%$, LEV by $44 \%$ and PHT by $37 \%$. ETX, VGB, VNS, and PB, were considered inadequate by $93 \%, 61 \%, 50 \%$, and $38 \%$ of the respondents.

\section{Elderly patients}

Carbamazepine was chosen by $77 \%$ of the respondents, followed by PHT (54\%) and LTG (52\%). As a second-choice LEV (67\%), GBP (46\%), and OXC (59\%) were chosen. Other options considered to be 'appropriate' were TPM (59\%), PB (50\%), VPA (48\%), and CLBZ (48\%). ETX (95\%), VNS (75\%), VGB $(67 \%)$, and TGB (59\%), were considered inadequate.

\section{Unclassified epilepsy}

\section{Young men}

Valproate was chosen by $68 \%$ of epileptologists, followed by CBZ (60\%), as the treatment of choice for this particular group. 'Appropriate' medications were TPM (62\%), LEV (57\%), LTG (54\%), and CLBZ (41\%). PB was considered to be 'rarely useful' by $50 \%$, GBP by $52 \%$ and OXC by $30 \%$. ETX was considered inadequate by $58 \%$, VGB by $52 \%$, TGB by $50 \%$ and VNS by $48 \%$.

\section{Women of childbearing age}

Lamotrigine was the first choice by $66 \%$ of the respondents, followed by CBZ (59\%). Considered 'appropriate' were LEV by $50 \%$, TPM by $48 \%$, VPA and CLBZ by $43 \%$, and PHT by $40 \%$. ETX, VNS, VGB, and PB, were considered inadequate by $72 \%$, $74 \%, 68 \%$, and $41 \%$ by the respondents, respectively.

\section{Elderly patients}

Lamotrigine was chosen by $61 \%$ of the respondents, followed by CBZ $(53 \%)$, VPA $(46 \%)$, and PHT $(42 \%)$. As a second-choice LEV (67\%), TPM (57\%), CLBZ (48\%), GBP (46\%), and OXC (33\%) were chosen. Other option considered to be 'appropriate' was PB (32\%). ETX (85\%), VNS (69\%), VGB (65\%), and TGB $(63 \%)$, were considered inadequate.

\section{Status epilepticus (Figure 3)}

Intravenous lorazepam (IV LZP) was by far the first choice in the treatment of status epilepticus, it was chosen by $95 \%$ of the respondents $(\mathrm{p}<0.001)$. PHT was considered by $51 \%(\mathrm{p}<0.001)$. As a second choice of treatment after a failed initial intervention, $72 \%$ chose intravenous PHT $(\mathrm{p}<0.001)$, while $64 \%$ of the respondents chose a second dose of IV LZP $(\mathrm{p}<0.001)$. 'Appropriate' choices were intravenous diazepam (IV DZP) by $46 \%$, intravenous phenobarbital by $41 \%$, and intravenous midazolam by $35 \%$ of the respondents as an initial treatment for status epilepticus. While intravenous midazolam, intravenous $\mathrm{PB}$, and intravenous VPA were considered 'appropriate' intervention by $43 \%, 42 \%$, and $37 \%$ of respondents, as a first choice after a failed initial intervention in status epilepticus.

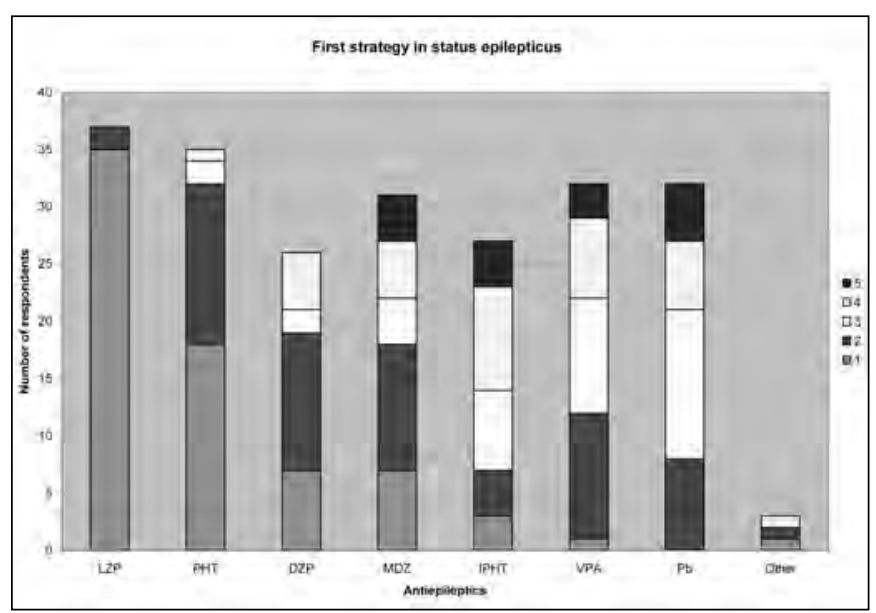

Figure 3: Responses chosen by Canadian epileptologists when asked about first treatment strategy in Status Epilepticus

\section{DISCUSSION}

The survey was able to identify the presence of a consensus between Canadian epileptologists on how to treat newly diagnosed patients with different epilepsy syndromes.

The first choice of AED depends on the form of epilepsy or epilepsy syndrome, which underlines the importance of the International League Against Epilepsy classification of the epilepsies. ${ }^{17}$

There are many clinical situations in which the best treatment approach is not established from evidence obtained through randomized controlled clinical trials. These are instances in which expert opinion can fill the gaps. By pooling the opinion of experts and analyzing the results, biases can be diminished. But, such an approach has some potential limitations. The experts may be wrong. This is a problem that plagues all surveys or opinion-driven guidelines. If the experts are too highly selected, this opinion may not be representative. ${ }^{14}$ We surveyed not only university based epileptologists, but those with practices in private settings, and included both adult and pediatric specialists from across the country.

The intention of this study was not to supercede data in the literature or replace clinical judgment; neither to suggest options that the clinician may wish to considers; it actually presents what clinicians with expertise in epilepsy would do when faced with a specific scenario. Furthermore, clinicians can compare their own practices against those of a panel of experts. It is of interest that the indications for which certain AEDs were approved by Health Canada or the Food and Drug Administration (FDA), do not necessarily match neurologists' practice (See Table).

The consensus is clear in the management of generalized epilepsy. Valproate is the favored antiepileptic drug in young men with Idiopathic Generalized Epilepsy, Juvenile Myoclonic Epilepsy, and Absence Epilepsy. Lamotrigine is the preferred in women of childbearing age with Idiopathic Generalized Epilepsy, Juvenile Myoclonic Epilepsy, and Absence Epilepsy. In the elderly, different antiepileptic drugs were chosen by the 
Table: Comparison between indications for the differenc AEDs and the results of the survey

\begin{tabular}{|c|c|c|}
\hline Antiepileptic Medication & FDA Approval & Survey Results \\
\hline Phenobarbital & Partial and generalized seizures & Not a preference \\
\hline Phenytoin & Partial and generalized seizures & Partial and generalized seizures \\
\hline Valproate & Partial and generalized seizures & Partial and generalized seizures \\
\hline Lamotrigine & Partial and generalized seizures & $\begin{array}{l}\text { Partial and generalized seizures } \\
\text { (monotherapy) }\end{array}$ \\
\hline Gabapentin & Partial seizures (add-on) & Partial seizures (monotherapy) \\
\hline Topiramate & Partial and generalized seizures & Partial and generalized seizures \\
\hline Oxcarbazepine & Partial seizures (add-on) & Partial seizures (monotherapy) \\
\hline Levetiracetam & Partial seizures (add-on) & $\begin{array}{l}\text { Partial and generalized seizures } \\
\text { (monotherapy) }\end{array}$ \\
\hline Vigabatrin & Partial seizures & Not a preference \\
\hline Tiagabine & Partial seizures & Not a preference \\
\hline Ethosuximide & Absence seizures & Absence seizures \\
\hline Clonazepam & Partial and generalized seizures & Not a preference \\
\hline Clobazam & Partial and generalized seizures & Partial and generalized seizures \\
\hline Vagus nerve stimulation & Partial seizures & Not a preference \\
\hline Carbamazepine & Partial and generalized seizures & Partial seizures \\
\hline Primidone & Partial and generalized seizures & Not a preference \\
\hline
\end{tabular}

respondents. Topiramate was considered an alternative or as second choice for the treatment of Absence Epilepsy and Juvenile Myoclonic Epilepsy in young men, while ethosuximide was preferred for women of childbearing age with Absence Epilepsy, and levetiracetam for men with Idiopathic Generalized Epilepsy. There was general consensus about the drugs that are not prescribed as first-line agents in the treatment of the generalized epilepsies: Vigabatrin, tiagabine, carbamazepine, and gabapentin. The list included the Vagus Nerve Stimulation. When our results are compared to the surveys in the US ${ }^{14}$ and France, ${ }^{15}$ conducted between 2000 and 2003, the practices are quite similar. The drugs chosen to treat were the same, with one exception. Lamotrigine was preferred over valproate by American neurologists.

Carbamazepine is the reference AED for the treatment of partial epilepsy in young men, women of childbearing age, and the elderly. Alternatives chosen by the respondents were variable, but the inclusion of clobazam marked a difference when compared with the US and French surveys.

Valproate can be considered as the first-line AED in young men, and lamotrigine in women of childbearing age. Less consensus was seen when treating the elderly, as a number of drugs were used about equally including phenytoin, lamotrigine, gabapentin, oxcarbazepine, carbamazepine, and clobazam.
An initial intervention with intravenous lorazepam, followed by either a second dose of the same drug or intravenous phenytoin was chosen by the respondents as the choice in the management of status epilepticus. The results are similar to the US survey, with the exception that fosphenytoin replaced our choice of phenytoin. Although dermal and systemic side effects are more likely with phenytoin than with fosphenytoin, a prodrug of phenytoin. ${ }^{18-20}$ The high cost of the latter drug precludes its use in many centers. The French survey did not assess management of status epilepticus.

The strategy adopted for the second treatment after failure of the first monotherapy included two approaches: immediate substitution monotherapy, and replacement of concomitant administration of the second drug, found to be efficient.

The results of our survey in combination with the US and French can be compared to the recommendations given by the Therapeutics and Technology Assessment Subcommittee and Quality Standards Subcommittee of the American Academy of Neurology and the American Epilepsy Society. ${ }^{9,10,21}$

In conclusion, this national survey demonstrated some consensus in the choice of AED for adult patients. Furthermore, the so-called "new AEDs" are being included in the daily armamentarium of treating epileptologists, while the "old AEDs" are being relegated with the exception of valproate, most likely due to safety data and the absence of interactions with other drugs. 


\section{REFERENCES}

1. Wheless JW, Venkataraman V. New formulations of drugs in epilepsy. Expert Opin Pharmacother. 1999;1(1):49-60.

2. Nadkarni S, LaJoie J, Devinsky O. Current treatments of epilepsy. Neurology. 2005;64(12 Suppl 3):S2-11.

3. Guyatt GH, Rennie D. Users' Guides to the Medical Literature. A Manual for Evidence-Based Clinical Practice. Chicago: AMA Press; 2002.

4. Williamson PR, Marson AG, Tudur C, Hutton JL, Chadwick D. Individual patient data meta-analysis of randomized antiepileptic drug monotherapy trials. J Eval Clin Pract. 2000; 6(2):205-14.

5. Privitera MD. Evidence-based medicine and antiepileptic drugs. Epilepsia. 1999;40 Suppl 5:S47-56.

6. Montori VM, Swiontkowski MF, Cook DJ. Methodologic issues in systematic reviews and meta-analyses. Clin Orthop Relat Res. 2003(413):43-54.

7. Burneo JG, Montori VM, Faught E. Magnitude of the placebo effect in randomized trials of antiepileptic agents. Epilepsy Behav. 2002;3(6):532-4.

8. Kwan P, Brodie MJ. Early identification of refractory epilepsy. N Engl J Med. 2000;342(5):314-9.

9. French JA, Kanner AM, Bautista J, Abou-Khaul B, Browne T, Harden CL, et al. Efficacy and tolerability of the new antiepileptic drugs II: treatment of refractory epilepsy: report of the Therapeutics and Technology Assessment Subcommittee and Quality Standards Subcommittee of the American Academy of Neurology and the American Epilepsy Society. Neurology. 2004;62(8):1261-73.

10. French JA, Kanner AM, Bautista J, Abou-Khaul B, Browne T, Harden CL, et al. Efficacy and tolerability of the new antiepileptic drugs I: treatment of new onset epilepsy: report of the Therapeutics and Technology Assessment Subcommittee and Quality Standards Subcommittee of the American Academy of Neurology and the American Epilepsy Society. Neurology. 2004;62(8):1252-60.

11. Brodie MJ, Kwan P. Staged approach to epilepsy management. Neurology. 2002;58(8 Suppl 5):S2-8.

12. Brodie MJ. Monostars: an aid to choosing an antiepileptic drug as monotherapy. Epilepsia. 1999;40 Suppl 6:S17-22; discussion S73-4.

13. Brodie MJ, Dichter MA. Antiepileptic drugs. N Engl J Med. 1996;334(3):168-75.

14. Karceski S, Morrell MJ, Carpenter D. Treatment of epilepsy in adults: expert opinion, 2005. Epilepsy Behav. 2005;7 Suppl 1:S1-64; quiz S5-7.

15. Semah F, Picot MC, Derambure P, Dupont S, Vercueil L, Chassagnon S, et al. The choice of antiepileptic drugs in newly diagnosed epilepsy: a national French survey. Epileptic Disord. 2004;6(4):255-65.

16. Clobazam in treatment of refractory epilepsy: the Canadian experience. A retrospective study. Canadian Clobazam Cooperative Group. Epilepsia. 1991;32(3):407-16.

17. Proposal for revised classification of epilepsies and epileptic syndromes. Commission on Classification and Terminology of the International League Against Epilepsy. Epilepsia. 1989;30(4):389-99.

18. O'Brien TJ, Cascino GD, So EL, Hanna DR. Incidence and clinical consequence of the purple glove syndrome in patients receiving intravenous phenytoin. Neurology. 1998;51(4):1034-9.

19. O'Brien TJ, Meara FM, Matthews H, Vajda FJ. Prospective study of local cutaneous reactions in patients receiving IV phenytoin. Neurology. 2001;57(8):1508-10.

20. Burneo JG, Anandan JV, Barkley GL. A prospective study of the incidence of the purple glove syndrome. Epilepsia. 2001;42(9):1156-9.
21. Glauser T, Ben-Menachem E, Bourgeois B, Cnaan A, Chadwick D, Guerreiro C, et al. ILAE treatment guidelines: evidence-based analysis of antiepileptic drug efficacy and effectiveness as initial monotherapy for epileptic seizures and syndromes. Epilepsia. 2006;47(7):1094-120.

\section{Appendix Survey questionnaire}

\section{Demographics}

What is your population of patients with epilepsy?(circle your answer)

a) Adults

b) Children

c) Both

\section{Treatment strategy}

In cases of failure of the first monotherapy, what do you do? (circle your answer)

a. Immediate substitution monotherapy (after a few days or a few weeks)

b. Add-on treatment, then monotherapy substitution after proven efficacy of the second antiepileptic agent (a few months)

c. Add-on therapy with a second antiepileptic agent.

If the second option fails, what do you do? (circle your answer)

a. Another substitution with monotherapy

b. Add-on treatment, then monotherapy substitution after proven efficacy of the third antiepileptic agent

c. Add-on therapy with a second antiepileptic agent

d. Combination of 3 antiepileptic agents

e. Referred patient to a surgical center / consider evaluation for epilepsy surgery

f. Vagus Nerve Stimulation (VNS)

g. Ketogenic diet

III. Choice of antiepileptic drug (AED)

a. Which antiepileptic agent do you use for monotherapy? (circle your answer for each antiepileptic)

When answering these questions please consider the following format:

$1=$ Extremely appropriate: it is your AED of choice (you may have several)

$2=$ Appropriate: the AED you use the most after your first choice

$3=$ Sometimes useful: an AED you sometimes use (i.e. in case of failure or contraindication of the other AED)

$4=$ Rarely useful=an AED that you rarely (or never) use or only in special cases

$5=$ Potentially harmful or totally inadequate

1. In young men without any other medical problem but epilepsy: which AED do you use for monotherapy?

a. In Idiopathic generalized epilepsy?

b. In Juvenile Myoclonic Epilepsy (JME)? 
c. In absence epilepsy?

d. In symptomatic or cryptogenic partial or focal epilepsy?

e. In unclassified epilepsy?

2. In women of childbearing age, considering pregnancy: which AED do you use for monotherapy?

a. In Idiopathic generalized epilepsy?

b. In Juvenile Myoclonic Epilepsy (JME)?

c. In absence epilepsy?

d. In symptomatic or cryptogenic partial or focal epilepsy?

e. In unclassified epilepsy?

3. In elderly patients: which AED do you use for monotherapy?

a. In Idiopathic generalized epilepsy?

b. In symptomatic or cryptogenic partial epilepsy?

c. In unclassified epilepsy?

Medications surveyed in each question:

$\begin{array}{llll}\text { Phenobarbital } & 1 & 2 & 3\end{array}$

$\begin{array}{llll}\text { Phenytoin } & 1 & 2 & 3\end{array}$

$\begin{array}{llll}\text { Valproate } & 1 & 2 & 3\end{array}$

Lamotrigine $\quad 1 \quad 2 \quad 3$

Gabapentin $\quad 1 \quad 2 \quad 3$

$\begin{array}{llll}\text { Topiramate } & 1 & 2 & 3\end{array}$

Oxcarbazepine 1123

Levetiracetam 1123

$\begin{array}{llll}\text { Vigabatrin } & 1 & 2 & 3\end{array}$

Tiagabine

Ethosuximide

Clonazepam

$\begin{array}{llllll}\text { Clobazam } & 1 & 2 & 3 & 4 & 5 \\ \text { VNS } & 1 & 2 & 3 & 4 & 5 \\ \text { Carbamazepine } & 1 & 2 & 3 & 4 & 5 \\ \text { Primidone } & 1 & 2 & 3 & 4 & 5 \\ \text { Other: } & 1 & 2 & 3 & 4 & 5\end{array}$

IV. In Status Epilepticus (partial or Generalized), what is your initial therapy?

$\begin{array}{llllll}\text { IV lorazepam } & 1 & 2 & 3 & 4 & 5 \\ \text { IV or rectal diazepam } & 1 & 2 & 3 & 4 & 5 \\ \text { IV phenytoin } & 1 & 2 & 3 & 4 & 5 \\ \text { IV or IM fosphenytoin } & 1 & 2 & 3 & 4 & 5 \\ \text { IV midazolam } & 1 & 2 & 3 & 4 & 5 \\ \text { IV valproate } & 1 & 2 & 3 & 4 & 5 \\ \text { IV Phenobarbital } & 1 & 2 & 3 & 4 & 5 \\ \text { Other: } & 1 & 2 & 3 & 4 & 5\end{array}$

If the first option fails, what is your second option?

$\begin{array}{llllll}\text { IV lorazepam again } & 1 & 2 & 3 & 4 & 5\end{array}$

$\begin{array}{llllll}\text { IV or rectal diazepam } & 1 & 2 & 3 & 4 & 5\end{array}$

$\begin{array}{llllll}\text { IV phenytoin } & 1 & 2 & 3 & 4 & 5\end{array}$

IV or IM fosphenytoin $1 \quad 2 \quad 3 \quad 4 \quad 5$

$\begin{array}{llllll}\text { IV midazolam } & 1 & 2 & 3 & 4 & 5\end{array}$

$\begin{array}{llllll}\text { IV valproate } & 1 & 2 & 3 & 4 & 5\end{array}$

IV Phenobarbital $\quad 1 \quad 2 \quad 3045$ 